\title{
Focused echocardiography
}

Citation for published version (APA):

See, K. C., Chua, J. W., Verstegen, D., Van Merrienboer, J. J. G., \& Van Mook, W. N. (2019). Focused echocardiography: Dyad versus individual training in an authentic clinical context. Journal of Critical Care, 49, 50-55. https://doi.org/10.1016/j.jcrc.2018.10.009

Document status and date:

Published: 01/02/2019

DOI:

10.1016/j.jcrc.2018.10.009

Document Version:

Publisher's PDF, also known as Version of record

Document license:

Taverne

Please check the document version of this publication:

- A submitted manuscript is the version of the article upon submission and before peer-review. There can be important differences between the submitted version and the official published version of record.

People interested in the research are advised to contact the author for the final version of the publication, or visit the DOI to the publisher's website.

- The final author version and the galley proof are versions of the publication after peer review.

- The final published version features the final layout of the paper including the volume, issue and page numbers.

Link to publication

\footnotetext{
General rights rights.

- You may freely distribute the URL identifying the publication in the public portal. please follow below link for the End User Agreement:

www.umlib.nl/taverne-license

Take down policy

If you believe that this document breaches copyright please contact us at:

repository@maastrichtuniversity.nl

providing details and we will investigate your claim.
}

Copyright and moral rights for the publications made accessible in the public portal are retained by the authors and/or other copyright owners and it is a condition of accessing publications that users recognise and abide by the legal requirements associated with these

- Users may download and print one copy of any publication from the public portal for the purpose of private study or research.

- You may not further distribute the material or use it for any profit-making activity or commercial gain

If the publication is distributed under the terms of Article $25 \mathrm{fa}$ of the Dutch Copyright Act, indicated by the "Taverne" license above, 


\title{
Focused echocardiography: Dyad versus individual training in an authentic clinical context 2 ?
}

\author{
Kay Choong See ${ }^{\mathrm{a}, \mathrm{d}, *}$, Joo Wei Chua a,d, Danielle Verstegen ${ }^{\mathrm{b}}$, \\ Jeroen J.G. Van Merrienboer ${ }^{\mathrm{b}}$, Walther N. Van Mook ${ }^{\mathrm{c}, \mathrm{e}}$ \\ a Division of Respiratory \& Critical Care Medicine, University Medicine Cluster, National University Health System, Singapore \\ ${ }^{\mathrm{b}}$ Department of Educational Research and Development, School of Health Professions Education, Maastricht University, Maastricht, the Netherlands \\ ${ }^{c}$ Department of Intensive Care Medicine, Academy for Postgraduate Medical Training, Maastricht University Medical Centre, Maastricht, the Netherlands \\ ${ }^{\mathrm{d}}$ Department of Medicine, Yong Loo Lin School of Medicine, National University of Singapore, Singapore \\ e School of Health Professions Education, Maastricht University, Maastricht, the Netherlands
}

\section{A R T I C L E I N F O}

\section{Keywords:}

Echocardiography

Ultrasonography

Education

Internship and residency

Intensive care units

Non-randomized controlled trials as topic

\begin{abstract}
A B S T R A C T
Purpose: Echocardiography is increasingly being taught to intensive care unit residents. Current training methods require teachers to closely supervise trainees individually, and are time-intensive. To reduce the time burden, dyad training (training in pairs) under simulation conditions has been shown to be non-inferior to individual training. We aimed to validate these preliminary results for focused subcostal echocardiography (FSE), in an authentic clinical context.

Materials and methods: We conducted a quasi-experimental study within a 20-bed medical intensive care unit from June 2016 to March 2017. For supervised practice, residents were divided into individual versus dyad training groups. Residents then performed at least five FSE examinations, which were remotely scored by a blinded observer for image quality and correct interpretation. The main outcome measure was the mean composite image quality and interpretation score for the first five echoes done under indirect supervision (composite score range 1-8).

Results: 16 residents received individual training and 17 residents received dyad training. The mean composite score did not differ between the individual and dyad training groups $(6.0 \pm 0.4$ versus $5.9 \pm 0.4,95 \% \mathrm{CI}$ of difference -0.2 to 0.4 ).

Conclusions: Assuming a 1-point non-inferiority threshold for the mean composite score, dyad training for FSE was non-inferior to individual training.
\end{abstract}

(c) 2018 Elsevier Inc. All rights reserved.

\section{Introduction}

The spread of critical care echocardiography technology and expertise has allowed intensive care unit (ICU) physicians to incorporate echocardiography into routine clinical practice. Given its utility, echocardiography has been proposed as a core skill for intensive care medicine physicians by several expert groups [1-6]. For learning complex procedures like

\footnotetext{
Abbreviations: FSE, Focused subcostal echocardiography; ICU, Intensive care unit. it This work was performed at the National University Hospital, Singapore. Part of this work was orally presented at the CHEST Annual Meeting, November 2017, Toronto, Canada.

* Corresponding author at: Division of Respiratory \& Critical Care Medicine, University Medicine Cluster, National University Health System, 1E Kent Ridge Road, NUHS Tower Block Level 10, 119228, Singapore.

E-mail addresses: kay_choong_see@nuhs.edu.sg (K.C. See),

joo_wei_chua@nuhs.edu.sg (J.W. Chua),d.verstegen@maastrichtuniversity.nl (D. Verstegen), j.vanmerrienboer@maastrichtuniversity.nl (J.J.G. Van Merrienboer), w.van.mook@mumc.nl (W.N. Van Mook).
}

echocardiography, skill acquisition requires both a theoretical foundation and hands-on (procedural) practice. During hands-on practice, teachers need to spend substantial time supervising novice trainees, which has led to efforts to improve training efficiency within time-constrained learning environments. One of these methods that is particularly suited for procedural tasks is dyad training [7-9], as opposed to individual training. During dyad training, two participants collaborate and interact to learn echocardiography, though they would eventually perform echocardiography independently.

The rationale for dyad training is that, firstly, it harnesses collaborative learning, allowing participants to observe one another $[8,10]$. Observation could then activate the same neural structures for practice (the mirror neuron effect) [11]. Secondly, dyad training leads to participants comparing themselves against one another. According to social comparison theory, such comparison with a peer can allow a learner to be more aware of one's shortcomings and strengths, the latter reinforcing learner confidence and motivation [12,13]. Thirdly, the cognitive load required for learning complex tasks could potentially be shared 
between two participants, facilitating learning [14]. Fourthly, dyad training, compared to individual training, effectively halves the instructor time required to train two trainees. Dyad training has been applied to bronchoscopy training [7], to coronary angiography training [15], to lumbar puncture training [16], to clinical skills training [17], and to obstetric ultrasound training [18]. However, these applications were studied in simulation scenarios, which may not be generalizable to the real world [15].

In our experience, a single subcostal echocardiographic view is sufficient to detect major abnormalities that would affect acute management of a critically ill patient (i.e. moderate/severe left ventricular dysfunction, dilated right ventricle, pericardial effusion $>20 \mathrm{~mm}$ in thickness) [19]. To demonstrate generalizability of dyad training to echocardiography in the real world [20], we therefore aimed to investigate if dyad training would be non-inferior to individual training for focused subcostal echocardiography (FSE), among ICU residents learning and performing the procedure within an authentic clinical context.

\section{Materials and methods}

\subsection{Study design, setting and participants}

A quasi-experimental study was conducted within a 20-bed medical ICU of a 1250-bed university hospital (National University Hospital, Singapore) from June 2016 to March 2017. This study design took advantage of the training schedule of the residents. The residents had three one-hour training slots within any week, with one slot earlier in the afternoon from 1400 to $1500 \mathrm{~h}$ (allowing two residents to train together as work would be less busy then), and two slots on separate days later in the afternoon from 1500 to $1600 \mathrm{~h}$ (allowing one resident to train at any one time as work would be more busy then). Each resident was required to attend one training slot only and this would effectively allocate residents to dyad versus individualized training in a $1: 1$ ratio. Furthermore, the sessions were tightly controlled for time, and could not exceed one hour each due to residents' work commitments. The allocation of residents was not fixed; rather, we fixed the training slots, and the residents who had the least duties during those slots were trained. Residents did not have influence over which training slot to attend.

Internal Medicine junior residents rotating into the medical ICU were included in the study. Residents who had prior echocardiography training in any form, or who did fewer than five cases after directly supervised training were excluded. As FSE training was a standard part of the ICU curriculum, written informed consent was not required. Ethical approval for the study was obtained from the National Healthcare Group Domain-Specific Review Board (2017/00119).

\subsection{Training phase}

FSE training was delivered by one trainer (Physician A, KCS) with five years of critical care echocardiography experience. From our prior experience with echocardiography, the vast majority of patients in our ICU are not excessively obese and satisfactory images would be possible [19]. Ultrasound scanning was done using the Sparq Ultrasound System (Philips Healthcare, Andover, MA) equipped with a 2-4 MHz broadband sector phased array transducer.

Training was done using a protocol involving self-directed learning from a standard slide deck, theoretical testing, practical demonstration, hands-on practice, and just-in-time feedback. Learning slides were sent to the participants 2-3 days before the theory test. The theory test (paper-based, 10 questions, 1 mark per question, $5 \mathrm{~min}$ ) (Supplementary Appendix 1), followed by the trainer giving a 5-min debrief, was done just before the practical training session. The practical training session with demonstration, hands-on practice, and just-in-time feedback, lasted a total of $50 \mathrm{~min}$ (with 2-4 patients being scanned). During dyad training, both trainees performed the ultrasound scan, one after another without a fixed order. The practical training duration did not differ for dyad and for individual training. Given the very narrow scope of basic echocardiography in our study (only one view and three interpretation points), approximately one hour of training should be sufficient to create an educational impact. Other studies have also designed similarly short periods of hands-on training for critical care ultrasound in general $[21,22]$, and for other focused techniques in ultrasonography [23,24].

\subsection{Evaluation phase}

Residents were expected to perform at least five subsequent FSE examinations, to save the cine images in the hard drive of the echocardiography machine, and to record their findings in the ICU electronic documentation system. Depending on clinical need, each patient could be scanned multiple times, and each time was considered as a separate case for the analysis. The echocardiographic cine images and documentation were then reviewed by an independent observer with two years of critical care echocardiography experience (Physician B, JWC) for image quality and accuracy of image interpretation [25]. To ensure reliability of assessment, Physicians A and B independently evaluated the image quality and interpretation of 10 FSE examinations done by residents excluded from the study, and achieved 100\% agreement. Physician B did not know the training status (dyad versus independent) of each resident.

Image acquisition quality was scored by Physician B on 5-point Likert scale according to the American College of Emergency Physicians' recommendation [26] (Table 1). A "3" of the American College of Emergency Physicians' grading scale was the minimum grade required for an adequate image. For images graded "2" or below, the observer would provide feedback to improve image acquisition, and the observer's image interpretation would be based upon supplementary information gathering by the independent observer.

Image interpretation accuracy was scored by Physician B as correct or incorrect for each of three individual features. Firstly, pericardial effusion, which can be none, small-moderate (1-20 mm in thickness) or large ( $>20 \mathrm{~mm}$ in thickness) [27]. Secondly, left ventricular function, which can be normal (visual ejection fraction $\geq 50 \%$ ) or depressed (visual ejection fraction $<50 \%$ ). Thirdly, right ventricular size, which can be normal-mildly dilated (visual right ventricle to left ventricle end-diastolic area $<1$ ) or severely dilated (visual right ventricle to left ventricle end-diastolic area $\geq 1$ ) [28].

Evaluation was based upon cases done under indirect supervision only. The overall score of each case (range 1-8 points) was taken as the sum of image acquisition quality (range 1-5 points) and image interpretation accuracy (range $0-3$ points). We gave more weight to image quality as a good image is key to accurate interpretation. We reasoned that the minimum clinically important difference would be 1 point, since a 1-point increase in composite score would be the minimum needed for either better image quality or an additional feature that was correctly interpreted.

To ensure patient safety, Physician B provided indirect supervision daily during office hours and gave telephonic feedback when errors of image acquisition or interpretation were detected. Residents were taught to link findings to management in the following way:

Table 1

Assessment scale for image quality.

\begin{tabular}{ll}
\hline Grade & Definition \\
\hline 1 & No recognizable structures. No objective data can be gathered \\
2 & Minimally recognizable structures. Image quality insufficient for diagnosis \\
3 & $\begin{array}{l}\text { Recognizable structures but with some technical or other flaws (e.g. } \\
\text { certain failures in the image's position, gain or depth). Image quality } \\
\text { minimally sufficient for diagnosis }\end{array}$ \\
4 & $\begin{array}{l}\text { All structures imaged well. Diagnosis easily supported } \\
\text { All structures imaged with excellent image quality. Diagnosis completely } \\
\text { supported }\end{array}$ \\
\end{tabular}


(1) large pericardial effusion triggered cardiology consultation; (2) left ventricular dysfunction triggered consideration of acute myocardial infarction and septic cardiomyopathy; (3) severe right ventricular dilatation triggered consideration of pulmonary embolism, fluid overload, and acute cor pulmonale. Patient safety was further assured by oversight of all clinical decisions by the ICU senior resident or consultant at all times.

\subsection{Statistical analysis and power consideration}

The main outcome measure was the mean composite score (range 1-8 points) for image quality and image interpretation, averaged across the first five cases done under indirect supervision by each participant. Assuming a significance level of 0.05 , an anticipated difference of zero, a non-inferiority limit of one-point, a population standard deviation of 0.75 , and a $1: 1$ allocation ratio, with $90 \%$ power, 20 residents were required. To demonstrate that using the first five cases done under indirect supervision would be fair reflection of longer term training outcomes, we investigated the score trajectory in incremental blocks of five echoes, using Cuzick's nonparametric test for trend [29].

\section{Results}

Out of 43 junior residents who received FSE training, 8 had prior echocardiography training and 2 did fewer than five cases after directly supervised training, leaving 33 participants (age $28.2 \pm 3.0$, 19 or $57.6 \%$ female) for analysis (Table 2). A total of 403 cases were completed and the patient characteristics are shown in Table 3.

Training outcomes were nearly identical for the individual and dyad training groups, with regard to theoretical test performance, number of echoes done, image quality and image interpretation (Table 4). For the main outcome measure, which was the mean composite score for the first five echoes done under indirect supervision, individual and dyad training had similar results $(6.0 \pm 0.4$ versus $5.9 \pm 0.4,95 \% \mathrm{CI}$ of difference -0.2 to 0.4 ). This fulfilled the condition of non-inferiority, assuming a non-inferiority threshold of 1-point. Furthermore, when we considered all the echoes each individual performed, the similarity of the mean composite score persisted $(6.2 \pm 0.5$ versus $6.1 \pm 0.3, P=.498)$.

Adjustment of the main outcome measure (mean composite score for image quality and image interpretation) for participant characteristics (age, gender, years after graduation from medical school, year of residency, and prior ultrasound (non-echocardiography) experience) also yielded a result nearly identical to the unadjusted one: 95\% CI of difference of individual training versus dyad training

Table 2

Participant characteristics.

\begin{tabular}{lllll}
\hline Characteristics & $\begin{array}{l}\text { All } \\
\text { participants } \\
(N=33)\end{array}$ & $\begin{array}{l}\text { Individual } \\
\text { training } \\
(N=16)\end{array}$ & $\begin{array}{l}\text { Dyad } \\
\text { training } \\
(N=17)\end{array}$ & P-value \\
\hline $\begin{array}{l}\text { Age, mean (SD) } \\
\text { Gender }\end{array}$ & $28.2(3.0)$ & $28.1(2.4)$ & $28.4(3.5)$ & 0.742 \\
$\quad$ Male (\%) & $14(42.4)$ & $6(37.5)$ & $8(47.1)$ & 0.728 \\
$\quad$ Female (\%) & $19(57.6)$ & $10(62.5)$ & $9(52.9)$ & \\
Years after graduation from & $3(2-5)$ & $3(2-5.5)$ & $4(3-5)$ & 0.449 \\
$\quad$ medical school, median (IQR) & & & & \\
Year of residency & & & & \\
$\quad$ 1st year (\%) & $1(3.0)$ & $0(0.0)$ & $1(5.9)$ & 0.305 \\
$\quad$ 2nd year (\%) & $25(75.8)$ & $14(87.5)$ & $11(64.7)$ & \\
$\quad$ 3rd year (\%) & $7(21.2)$ & $2(12.5)$ & $5(29.4)$ & \\
Prior ultrasound & $13(39.4)$ & $6(37.5)$ & $7(41.2)$ & 1.000 \\
$\quad$ non-echocardiography) & & & & \\
$\quad$ experience & & & &
\end{tabular}

IQR: Interquartile range, SD: Standard deviation.
Table 3

Case characteristics.

\begin{tabular}{|c|c|c|c|c|}
\hline Characteristics & $\begin{array}{l}\text { All cases } \\
(N=403)\end{array}$ & $\begin{array}{l}\text { Individual training } \\
\text { cases }(N=198)\end{array}$ & $\begin{array}{l}\text { Dyad training } \\
\text { cases }(N=205)\end{array}$ & P-value \\
\hline $\begin{array}{l}\text { Age (years), mean } \\
\text { (SD) }\end{array}$ & $62.7(16.0)$ & $60.9(17.3)$ & $64.4(14.5)$ & 0.028 \\
\hline Gender & & & & 0.918 \\
\hline Male (\%) & $252(62.5)$ & $123(62.1)$ & $129(62.9)$ & \\
\hline Female (\%) & $151(37.5)$ & $75(37.9)$ & $76(37.1)$ & \\
\hline $\begin{array}{l}\text { Height }(\mathrm{m}) \text {, mean } \\
\quad(\mathrm{SD})\end{array}$ & $1.60(0.10)$ & $1.61(0.10)$ & $1.60(0.10)$ & 0.222 \\
\hline $\begin{array}{r}\text { Weight }(\mathrm{kg}) \text {, } \\
\text { mean }(\mathrm{SD})\end{array}$ & $62.5(14.8)$ & $62.5(15.2)$ & $62.5(14.6)$ & 0.996 \\
\hline $\begin{array}{l}\text { Body-mass index } \\
\left(\mathrm{kg} / \mathrm{m}^{2}\right) \text {, mean } \\
(\mathrm{SD})\end{array}$ & $24.6(6.6)$ & $24.3(6.2)$ & $24.8(6.9)$ & 0.459 \\
\hline \multicolumn{5}{|l|}{ Primary diagnosis } \\
\hline Pneumonia (\%) & $151(37.5)$ & 79 (39.9) & $72(35.1)$ & 0.618 \\
\hline Urosepsis (\%) & $16(4.0)$ & $6(3.0)$ & 19 (4.9) & \\
\hline $\begin{array}{l}\text { Intraabdominal } \\
\text { sepsis (\%) }\end{array}$ & $41(10.2)$ & $16(8.1)$ & $25(12.2)$ & \\
\hline $\begin{array}{l}\text { Asthma/COPD } \\
(\%)\end{array}$ & $31(7.7)$ & $17(8.6)$ & $14(6.8)$ & \\
\hline $\begin{array}{l}\text { Acute } \\
\text { myocardial } \\
\text { infarction (\%) }\end{array}$ & $27(6.7)$ & $10(5.1)$ & $17(8.3)$ & \\
\hline Fluid overload & $26(6.5)$ & $11(5.6)$ & $15(7.3)$ & \\
\hline Stroke (\%) & $27(6.7)$ & $15(7.6)$ & $12(5.9)$ & \\
\hline $\begin{array}{l}\text { Intestinal tract } \\
\text { bleeding (\%) }\end{array}$ & $28(7.0)$ & $13(6.6)$ & $15(7.3)$ & \\
\hline Seizure (\%) & $13(3.2)$ & $8(4.0)$ & $5(2.4)$ & \\
\hline Other $^{\mathrm{a}}(\%)$ & $43(10.7)$ & $23(11.6)$ & $20(9.8)$ & \\
\hline \multicolumn{5}{|c|}{$\begin{array}{l}\text { Mechanical } \\
\text { ventilation at } \\
\text { time of scanning }\end{array}$} \\
\hline Yes (\%) & $153(38.0)$ & $82(41.4)$ & $71(34.6)$ & 0.182 \\
\hline No (\%) & $250(62.0)$ & $116(58.6)$ & $134(65.4)$ & \\
\hline \multicolumn{5}{|l|}{$\begin{array}{l}\text { Pericardial } \\
\text { effusion }^{\text {b }}\end{array}$} \\
\hline None (\%) & $264(65.5)$ & $133(67.2)$ & $131(63.9)$ & 0.724 \\
\hline $\begin{array}{l}\text { Small }(<2 \mathrm{~cm} \\
\text { thickness) (\%) }\end{array}$ & $134(33.3)$ & $63(31.8)$ & $71(34.6)$ & \\
\hline $\begin{array}{l}\text { Large }(2 \mathrm{~cm} \text { or } \\
\text { greater })(\%)\end{array}$ & $5(1.2)$ & $2(1.0)$ & $3(1.5)$ & \\
\hline \multicolumn{5}{|l|}{$\begin{array}{l}\text { Left ventricular } \\
\text { function }{ }^{\mathrm{b}}\end{array}$} \\
\hline Normal (\%) & $323(80.1)$ & $157(79.3)$ & $166(81.0)$ & 0.709 \\
\hline Depressed (\%) & $80(19.9)$ & $41(20.7)$ & $39(19.0)$ & \\
\hline \multicolumn{5}{|l|}{$\begin{array}{l}\text { Ratio of } \\
\text { right-to-left } \\
\text { ventricle size }^{\mathrm{b}}\end{array}$} \\
\hline$<1(\%)$ & 389 (96.5) & $193(97.5)$ & 196 (95.6) & 0.417 \\
\hline 1 or greater $(\%)$ & $14(3.5)$ & $5(2.5)$ & $9(4.4)$ & \\
\hline \multicolumn{5}{|l|}{$\begin{array}{l}\text { Any } \\
\text { echocardio- } \\
\text { graphic finding }\end{array}$} \\
\hline Absent ${ }^{\mathrm{C}}$ & 201 (49.9) & $97(49.0)$ & $104(50.7)$ & 0.765 \\
\hline Present & $202(50.1)$ & $101(51.0)$ & $101(49.3)$ & \\
\hline
\end{tabular}

NB. A patient could be scanned several times, and each time was considered as a separate case for the analysis. For the individual training group 128 patients were scanned 198 times; for the dyad training group 149 were scanned 205 times; in total 277 patients were scanned 403 times.

COPD: Chronic obstructive pulmonary disease.

SD: Standard deviation.

a E.g. meningitis, septic arthritis, liver failure, lung cancer, lymphoma, pulmonary embolism, diabetic ketoacidosi.

b Based on characteristics determined by the faculty (Physician B), rather than by the trainee (participant).

c Defined as presence of any pericardial effusion or depressed left ventricular function or ratio of right-to-left ventricle size of 1 or greater. These characteristics are as determined by the faculty (Physician B), rather than by the trainee (participant).

-0.1 to 0.5 . As more echoes were done, the composite image quality and interpretation score had a statistically significant increase $(6.0$ to 6.2 to 6.3 to 6.4 ) (Table 5). Participants however demonstrated no significant improvement of mean composite scores from the first to the fifth echo (Table 6). 
Table 4

Training outcomes.

\begin{tabular}{|c|c|c|c|}
\hline & $\begin{array}{l}\text { Individual training } \\
(N=16)\end{array}$ & $\begin{array}{l}\text { Dyad training } \\
(N=17)\end{array}$ & P-value \\
\hline \multicolumn{4}{|c|}{ Theoretical test performance } \\
\hline \multicolumn{4}{|c|}{ Theoretical test score } \\
\hline Mean (SD) & $7.3(2.1)$ & $7.3(1.1)$ & 0.975 \\
\hline \multicolumn{4}{|c|}{ Number of echoes done } \\
\hline \multicolumn{4}{|c|}{$\begin{array}{l}\text { Number of echoes done } \\
\text { under indirect supervision }\end{array}$} \\
\hline Mean (SD) & $12.2(6.6)$ & $12.1(5.7)$ & 0.953 \\
\hline Median (IQR) & $10.5(7.5-16)$ & $12(7-14)$ & 0.899 \\
\hline Minimum & 5 & 5 & \\
\hline Maximum & 27 & 24 & \\
\hline \multicolumn{4}{|c|}{$\begin{array}{l}\text { Mean score for first five } \\
\text { echoes, done under } \\
\text { indirect supervision }\end{array}$} \\
\hline \multicolumn{4}{|c|}{ Composite score $^{a}$} \\
\hline \multirow[t]{2}{*}{ Mean (SD) } & $6.0(0.4)$ & $5.9(0.4)$ & 0.445 \\
\hline & Mean I-D $(95 \% \mathrm{CI})=$ & $.1(-0.2$ to 0.4$)$ & \\
\hline \multicolumn{4}{|c|}{ Image quality score } \\
\hline \multirow[t]{2}{*}{ Mean (SD) } & $3.4(0.3)$ & $3.2(0.4)$ & 0.241 \\
\hline & Mean I-D $(95 \% \mathrm{CI})=$ & $.2(-0.2$ to 0.4$)$ & \\
\hline \multicolumn{4}{|c|}{ Image interpretation score } \\
\hline \multirow{2}{*}{ Mean (SD) } & $2.7(0.2)$ & $2.7(0.2)$ & 0.599 \\
\hline & Mean I-D $(95 \% \mathrm{CI})=$ & $.0(-0.2$ to 0.1$)$ & \\
\hline \multicolumn{4}{|c|}{$\begin{array}{l}\text { Mean score for all echoes, } \\
\text { done under indirect } \\
\text { supervision }^{\mathrm{b}}\end{array}$} \\
\hline \multicolumn{4}{|c|}{ Composite score $\mathrm{e}^{\mathrm{a}}$} \\
\hline \multirow[t]{2}{*}{ Mean (SD) } & $6.2(0.5)$ & $6.1(0.3)$ & 0.498 \\
\hline & Mean I-D $(95 \% \mathrm{CI})=$ & $.1(-0.2$ to 0.4$)$ & \\
\hline \multicolumn{4}{|c|}{ Image quality score } \\
\hline \multirow[t]{2}{*}{ Mean (SD) } & $3.4(0.3)$ & $3.3(0.3)$ & 0.351 \\
\hline & Mean I-D $(95 \% \mathrm{CI})=$ & $.1(-0.1$ to 0.3$)$ & \\
\hline \multicolumn{4}{|c|}{ Image interpretation score } \\
\hline \multirow[t]{2}{*}{ Mean (SD) } & $2.8(0.3)$ & $2.8(0.1)$ & 0.928 \\
\hline & Mean I-D $(95 \% \mathrm{CI})=$ & $.0(-0.2$ to 0.2$)$ & \\
\hline
\end{tabular}

\section{CI; Confidence interval.}

I-D: Individual training score minus dyad training score.

IQR: Interquartile range.

SD: Standard deviation.

a Composite score (score range 1-8) is the sum of image quality score (score range 1-5) and image interpretation score (score range $0-3$ ).

b Scores for each participant were averaged across all the echoes by each participant under indirect supervision.
Table 6

Trajectory of scores for the first 5 echoes performed under indirect supervision.

\begin{tabular}{llllll}
\hline Test scores & 1st echo & 2nd echo & 3rd echo & 4th echo & 5th echo \\
\hline $\begin{array}{l}\text { Number of cases } \\
\text { Number of participants }\end{array}$ & 33 & 33 & 33 & 33 & 33 \\
$\quad \begin{array}{l}\text { performing the echoes } \\
\text { Composite score }\end{array}$ & & 33 & 33 & 33 & 33 \\
$\quad \begin{array}{lllll}\text { Mean (SD) } \\
\text { Image quality score }\end{array}$ & $5.8(0.9)$ & $6.1(0.7)$ & $5.8(0.7)$ & $6.1(0.9)$ & \\
$\quad$ Mean (SD) & $3.1(0.6)$ & $3.4(0.7)$ & $3.1(0.5)$ & $3.5(0.8)$ & \\
$\begin{array}{l}\text { Image interpretation score } \\
\quad \text { Mean (SD) }\end{array}$ & $2.7(0.5)$ & $2.8(0.4)$ & $2.7(0.5)$ & $2.7(0.5)$ & $2.7(0.5)$ \\
$\quad$ P-value & $\mathrm{NA}$ & 0.088 & 0.756 & 0.127 & 0.178 \\
\hline
\end{tabular}

NA: Not applicable.

SD: Standard deviation.

a Composite score (score range 1-8) is the sum of image quality score (score range 1-5) and image interpretation score (score range $0-3$ ).

b $P$-value for the composite score, taking the composite score for the 1 st echo as the reference value.

\section{Discussion}

Satisfactory balance of participant and patient characteristics between the individual and dyad training groups for FSE was observed in this quasi-experimental study. Compared to individual training, dyad training resulted in non-inferior mean composite score, mean image quality score, and mean image interpretation score.

The training outcomes were satisfactory, as the image quality scores exceeded three, which was the American College of Emergency Physicians' minimum grade required for an adequate image. The mean image interpretation scores were nearly three, which meant that participants usually identified all the key abnormalities correctly. As participants did more echoes, the mean composite and image quality scores increased, though the increments were very small (maximal increment $<7 \%$ of the baseline score) and were clinically not significant. This relatively flat trajectory of score increments demonstrated that using the first five cases done under indirect supervision may be a fair reflection of longer term training outcomes. At the same time, a spread of composite scores were achieved by participants (see Fig. 1 for the density histogram), suggesting the absence of floor or ceiling effects, and that our chosen outcome measure was able to detect differences in trainee performance.

In line with theoretical expectations, dyad training was not inferior to individual training. Although each participant had less hands-on practice during dyad training compared to individual training, this was compensated adequately by collaborative learning. During dyad training, we observed that participants did not interact much, but rather

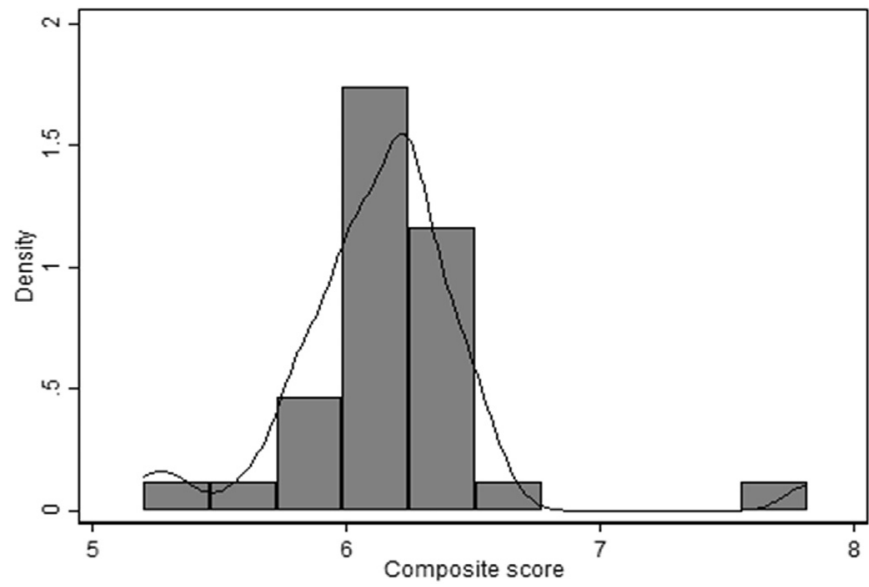

Fig. 1. Density histogram of the mean composite score for all echoes, done under indirect supervision.
Table 5

Trajectory of scores for cases performed under indirect supervision.

\begin{tabular}{llllll}
\hline Test scores & $\begin{array}{l}1-5 \\
\text { echoes }\end{array}$ & $\begin{array}{l}6-10 \\
\text { echoes }\end{array}$ & $\begin{array}{l}11-15 \\
\text { echoes }\end{array}$ & $\begin{array}{l}16+ \\
\text { echoes }\end{array}$ & P-value $^{\text {b }}$ \\
\hline $\begin{array}{l}\text { Number of cases } \\
\text { Number of participants performing }\end{array}$ & 165 & 121 & 71 & 46 & NA \\
$\quad \begin{array}{l}\text { the echoes } \\
\text { Composite score }\end{array}$ & & 28 & 18 & 8 & NA \\
$\quad \begin{array}{llll}\text { Mean (SD) } \\
\text { Image quality score }\end{array}$ & 6.0 & 6.2 & 6.3 & 6.4 & $<0.001$ \\
$\quad$ Mean (SD) & $(0.8)$ & $(0.8)$ & $(1.0)$ & $(0.8)$ & \\
$\begin{array}{l}\text { Image interpretation score } \\
\quad \text { Mean (SD) }\end{array}$ & 3.3 & 3.4 & 3.6 & 3.6 & $<0.001$ \\
& $(0.7)$ & $(0.6)$ & $(0.7)$ & $(0.7)$ & \\
& 2.7 & 2.8 & 2.7 & 2.8 & 0.139 \\
& $(0.5)$ & $(0.5)$ & $(0.7)$ & $(0.4)$ &
\end{tabular}

NA: Not applicable.

SD: Standard deviation.

a Composite score (score range 1-8) is the sum of image quality score (score range 1-5) and image interpretation score (score range $0-3$ ).

b Using Cuzick's nonparametric test for trend. 
learnt from both correct and incorrect actions made by their partners. This can be explained by social comparison theory, whereby peer learners tend to relate information about others to oneself [13]. If their partners did something right, participants would reproduce that action, so as to enhance their own ability. If their partners did something wrong while they did it right, participants would then feel more confident and motivated to do well.

Logically, the results of this study could be extrapolated to the learning of skills other than echocardiography, as long as the learning process involved is similar. The process would include initial theoretical training and testing, directly supervised hands-on performance, and indirectly supervised self-performance of a focused skill. Skill complexity should not matter, since complex tasks can be broken down into simpler subroutines, and dyad training could be applied to each of these subroutines. Therefore, apart from FSE training, it is possible that dyad training would also be non-inferior to individual training for other components of point-of-care ultrasound and other procedures, and more real-world studies in other fields should be done.

Our study had several strengths. We had the opportunity to compare the training outcomes of dyad versus individual training for FSE in the real world setting, rather than in simulation. This real world application bolsters the generalizability of dyad training in the learning of practical skills [20]. We also managed to blind our outcome assessor (Physician B) to the training group, as scoring took place off-line using saved images and electronic documentation only. This method eliminated the bias inherent in direct supervisor-trainee interactions. Moreover, we effectively used the quasi-experimental study design to attain satisfactory balance of baseline characteristics between the dyad and individual training groups. Such a quasi-experimental design involving all ICU residents would have three advantages over prior studies. Firstly, compared to simulation studies, it more accurately reflects real world learning outcomes. Secondly, when compared to a trial which would inevitably recruit only motivated participants, it may more accurately reflect the range of learning outcomes from a trainees of both lower and higher motivation levels. Thirdly, compared to a randomized controlled trial, using a quasi-experimental study will not require the underlying hypothesis of the study to be revealed, reducing both participant-related and observer-related bias.

We acknowledge that several limitations exist. Firstly, the study design is quasi-experimental and does not involve true randomization. Nonetheless, from Table 1 , the known baseline characteristics were well-balanced, and it appears that the quasi-experimental model was successful in simulating true randomization. Secondly, most participants were not ultrasound-naïve, though they were echocardiographynaïve. Prior knowledge about ultrasound could accelerate their learning. This is unavoidable as ultrasound is widely available in contemporary medicine, especially to improve the safety of vascular and pleural procedures. In any case, prior experience with non-echocardiography ultrasound techniques was well-balanced between the dyad and individual training groups, and would likely not have biased the test scores. Thirdly, our dyad training could only happen earlier in the afternoon as the ICU would be less busy then. While it is possible that dyad training participants could be less fatigued than individual training participants, the time difference between the dyad and individual training slots was only one hour. This short period of time was unlikely to have produced significant differences in learning aptitude. Fourthly, we only allowed a maximum of two participants per group. As such, our results may not apply to group training where more than two participants learnt together. Fifthly, we trained participants in only one subcostal view, and extrapolation of our results to other echocardiographic views requires further validation. Sixthly, although imaging difficulty would be variable in different patients, we believe that on aggregate, given similar body-mass indices (Table 3 ), imaging difficulty would be similar between the dyad and individual training groups. Seventhly, indirect supervision after directly-supervised training could complement learning of ultrasound skills. But the former's influence would be minor, given the similarity of scores between the individual and dyad training groups for the first five cases, and the relatively flat trajectory of score improvement after the first five cases. Finally, we were not able to test the ability of participants to integrate their echocardiography findings into actual clinical scenarios, as all clinical decisions would have been vetted by senior ICU team members to ensure patient safety.

After considering the limitations above, the findings of this study can perhaps stimulate echocardiography training programs to use dyad training methods, which can help save faculty time by $50 \%$. Such savings would help overcome the time constraints when spreading echocardiography training to areas beyond critical care, such as general internal medicine [30] and undergraduate medical curricula [31]. To further improve the sustainability of echocardiography teaching, indirect supervision done by Physician B can be replaced by workplace-based supervision by senior residents and staff. Similar to what was done for indirect supervision, junior residents would have to get at least five echoes endorsed by the senior members of their team before the former obtained a certificate of completion of training.

In conclusion, this study demonstrated that dyad training was noninferior to individual training for FSE in an authentic clinical context, in terms of image acquisition quality and image interpretation accuracy. If dyad training were to be adopted, faculty time would be reduced by $50 \%$, lessening the time-related cost of education and improving longer-term sustainability of FSE training.

\section{Acknowledgements}

KCS had full access to all the data in the study and takes responsibility for the integrity of the data and the accuracy of the data analysis. KCS, JWC, DV, JJvM, and WNvM jointly conceived the study and prepared the manuscript; KCS and JWC performed the data extraction; KCS performed the data analysis; DV, JJvM and WNvM supervised the analysis and edited the manuscript. The authors thank Dr. Chan Yiong Huak, Yong Loo Lin School of Medicine, National University of Singapore, for providing independent statistical review of this manuscript.

\section{Declaration of interest}

Declarations of interest: none.

\section{Funding}

This research did not receive any specific grant from funding agencies in the public, commercial, or not-for-profit sectors.

\section{Appendix A. Supplementary data}

Supplementary data to this article can be found online at https:// doi.org/10.1016/j.jcrc.2018.10.009.

\section{References}

[1] Arntfield R, Millington S, Ainsworth C, Arora R, Boyd J, Finlayson G, et al. Canadian recommendations for critical care ultrasound training and competency. Can Respir J 2014;21(6):341-5.

[2] Frankel HL, Kirkpatrick AW, Elbarbary M, Blaivas M, Desai H, Evans D, et al. Guidelines for the Appropriate use of Bedside General and Cardiac Ultrasonography in the Evaluation of Critically Ill Patients-Part I: General Ultrasonography. Crit Care Med 2015;43(11):2479-502.

[3] Neri L, Storti E, Lichtenstein D. Toward an ultrasound curriculum for critical care medicine. Crit Care Med 2007;35(5 Suppl):S290-304.

[4] Price S, Via G, Sloth E, Guarracino F, Breitkreutz R, Catena E, et al. Echocardiography practice, training and accreditation in the intensive care: document for the World Interactive Network Focused on critical Ultrasound (WINFOCUS). Cardiovasc Ultrasound 2008;6:49.

[5] Via G, Hussain A, Wells M, Reardon R, Elbarbary M, Noble VE, et al. International evidence-based recommendations for focused cardiac ultrasound. J Am Soc Echocardiogr 2014;27(7) (683 e1- e33).

[6] Cholley BP, Vieillard-Baron A, Mebazaa A. Echocardiography in the ICU: time for widespread use! Intensive Care Med 2006;32(1):9-10. 
[7] Bjerrum AS, Eika B, Charles P, Hilberg O. Dyad practice is efficient practice: a randomised bronchoscopy simulation study. Med Educ 2014;48(7):705-12.

[8] Crook AE, Beier ME. When training with a partner is inferior to training alone: the importance of dyad type and interaction quality.J Exp Psychol Appl 2010;16(4):335-48.

[9] Shea $\mathrm{CH}$, Wulf $\mathrm{G}$, Whitacre $\mathrm{C}$. Enhancing training efficiency and effectiveness through the use of Dyad training. J Mot Behav 1999;31(2):119-25.

[10] Granados C, Wulf G. Enhancing motor learning through dyad practice: contributions of observation and dialogue. Res Q Exerc Sport 2007;78(3):197-203.

[11] Gallese V, Goldman A. Mirror neurons and the simulation theory of mind-reading. Trends Cogn Sci 1998;2(12):493-501.

[12] Raat AN, Kuks JB, van Hell EA, Cohen-Schotanus J. Peer influence on students' estimates of performance: Social comparison in clinical rotations. Med Educ 2013;47(2):190-7.

[13] Raat AN, Cohen-Schotanus J. Dyad practice and the inevitability of social comparison. Med Educ 2014;48(7):652-4.

[14] Kirschner F, Paas F, Kirschner PA. A Cognitive load Approach to Collaborative Learning: United Brains for complex Tasks. Educ Psychol Rev 2009;21(1):31-42.

[15] Rader SB, Henriksen AH, Butrymovich V, Sander M, Jorgensen E, Lonn L, et al. A study of the effect of dyad practice versus that of individual practice on simulation-based complex skills learning and of students' perceptions of how and why dyad practice contributes to learning. Acad Med 2014;89(9):1287-94.

[16] Shanks D, Brydges R, den Brok W, Nair P, Hatala R. Are two heads better than one? Comparing dyad and self-regulated learning in simulation training. Med Educ 2013; 47(12):1215-22.

[17] Tolsgaard MG, Bjorck S, Rasmussen MB, Gustafsson A, Ringsted C. Improving efficiency of clinical skills training: a randomized trial. J Gen Intern Med 2013;28(8): 1072-7.

[18] Tolsgaard MG, Madsen ME, Ringsted C, Oxlund BS, Oldenburg A, Sorensen JL, et al. The effect of dyad versus individual simulation-based ultrasound training on skills transfer. Med Educ 2015;49(3):286-95.

[19] See KC, Ong V, Ng J, Tan RA, Phua J. Basic critical care echocardiography by pulmonary fellows: learning trajectory and prognostic impact using a minimally resourced training model*. Crit Care Med 2014;42(10):2169-77.
[20] Goodman SN, Fanelli D, Ioannidis JP. What does research reproducibility mean? Sci Transl Med 2016;8(341):341ps12.

[21] Chalumeau-Lemoine L, Baudel JL, Das V, Arrive L, Noblinski B, Guidet B, et al. Results of short-term training of naive physicians in focused general ultrasonography in an intensive-care unit. Intensive Care Med 2009;35(10):1767-71.

[22] Steinmetz P, Oleskevich S, Lewis J. Acquisition and long-term retention of bedside ultrasound skills in first-year medical students. J Ultrasound Med 2016;35(9): 1967-75.

[23] Vigneau C, Baudel JL, Guidet B, Offenstadt G, Maury E. Sonography as an alternative to radiography for nasogastric feeding tube location. Intensive Care Med 2005;31 (11):1570-2.

[24] Maury E, Guglielminotti J, Alzieu M, Guidet B, Offenstadt G. Ultrasonic examination: an alternative to chest radiography after central venous catheter insertion? Am J Respir Crit Care Med 2001;164(3):403-5.

[25] Arntfield RT. The utility of remote supervision with feedback as a method to deliver high-volume critical care ultrasound training. J Crit Care 2015;30(2) (441 e1-6).

[26] American College of Emergency Physicians. Emergency Ultrasound Standard Reporting Guidelines; 2011.

[27] Adler Y, Charron P, Imazio M, Badano L, Baron-Esquivias G, Bogaert J, et al. 2015 ESC guidelines for the diagnosis and management of pericardial diseases: the Task Force for the Diagnosis and Management of Pericardial Diseases of the European Society of Cardiology (ESC)Endorsed by: the European Association for Cardio-Thoracic Surgery (EACTS). Eur Heart J 2015;36(42):2921-64.

[28] Jardin F, Dubourg O, Bourdarias JP. Echocardiographic pattern of acute cor pulmonale. Chest 1997;111(1):209-17.

[29] Cuzick J. A Wilcoxon-type test for trend. Stat Med 1985;4(1):87-90.

[30] Schnobrich DJ, Mathews BK, Trappey BE, Muthyala BK, Olson APJ. Entrusting internal medicine residents to use point of care ultrasound: Towards improved assessment and supervision. Med Teach 2018:1-6.

[31] Wakefield RJ, Weerasinghe A, Tung P, Smith L, Pickering J, Msimanga T, et al. The development of a pragmatic, clinically driven ultrasound curriculum in a UK medical school. Med Teach 2018;40(6):600-6. 